\title{
A economia criativa e o valor potencial da Escola de Comunicações e Artes
}

Creative economics and the potential value of the School of Communications and Arts

La economía creativa y el valor potencial de la Escuela de Comunicación y Artes

Guilherme Fráguas Nobre

- Pós-doutor pela Université Stendhal, França

- Pós-doutorando da Escola de Comunicações e Artes da Universidade de São Paulo (ECA-USP) em 2014-2015

- Doutor em Ciências da Comunicação pela ECA-USP

- Mestre em Desenvolvimento Econômico pela Universidade Federal do Paraná (UFPR)

- Graduado em Ciências Econômicas pela Universidade Federal de Minas Gerais (UFMG)

- Afiliação à Universidade de São Paulo e à Universidad de Girona, Catalunha, Espanha

- Visiting Scholar na McMaster University, Canadá

- Pesquisador associado do Instituto Ciência-Tecnologia da Comunicação

- E-mail: fraguasnobre@gmail.com 


\section{Resumo}

0 artigo é composto por oito seções, além da introdução e das considerações finais. A primeira seção apresenta a economia criativa. A segunda aborda a economia imaterial, já que a economia criativa é, igualmente, intangível e simbólica. Os setores da economia criativa são qualificados na terceira seção e quantificados na quarta seção. A quinta seção analisa a economia tradicional, que poderia evoluir para ser mais criativa de acordo com a sexta seção. A atual relação da ECA-USP com a economia criativa é assunto da sétima seção, a o passo que a oitava seção tem foco no futuro para sugerir caminhos possíveis e potencialmente promissores.

\section{PALVRAS-CHAVE: ECONOMIA CRIATIVA・VALOR REAL E POTENCIAL・ESCOLA DE COMUNICAÇÕES E ARTES.}

\section{Abstract}

The article consists of eight sections, including the introduction and the final conclusion. The first section presents the creative economics. The second one addresses the immaterial economics, since creative economics is likewise intangible and symbolic. The sectors of creative economics are identified in the third section and quantified in the fourth section. The fifth section analyzes the traditional economics, which could evolve to become the most creative one pursuant to the sixth section. The current relationship between the ECA-USP and creative economics is the subject-matter of the seventh section, while the eighth section focuses on the future to suggest possible and potentially promising paths.

\section{KEYWORDS: CREATIVE ECONOMICS・REAL AND POTENTIAL VALUE・SCHOOL OF COMMUNICATIONS AND ARTS,}

\section{Resumen}

El artículo está compuesto por ocho secciones, incluyendo la introducción y la conclusión. La primera sección presenta la economía creativa. La segunda sección discute la economía inmaterial, ya que la economía creativa también es intangible y simbólica. Los sectores de la economía creativa san son calificados en la tercera sección, y cuantificados en la cuarta sección. La quinta sección analiza la economía tradicional, que podría evolucionar para ser más creativa de acuerdo con la sexta sección. La actual relación de la ECA-USP con la economía creativa es el tema de la séptima sección, mientras que la octava sección se centra en el futuro para sugerir caminos posibles y potencialmente prometedores. 
A economia criativa vem se tornando uma prioridade das políticas públicas em vários países, incluindo o Brasil - que $\triangle$ instituiu formalmente sua Secretaria da Economia Criativa pelo Decreto 7743, de $1^{0}$ de junho de 2012. Nascida e promovida em ambientes anglo-saxões (Austrália e Reino Unido), a terminologia expressa a crença de que o futuro do desenvolvimento econômico depende da criatividade, do talento e da inovação das pessoas, recursos intangíveis abundantes em alguns setores da economia.

Adicionalmente à qualificação e quantificação de tais setores, o objetivo deste artigo é pôr em evidência o valor da Escola de Comunicações e Artes da Universidade de São Paulo (ECA-USP) para a economia criativa brasileira e vice-versa. Se, por um lado, a ECA já está profundamente identificada e imbricada com os setores criativos relevantes para a nova economia, por outro lado restaria, ainda, muito a fazer para reposicioná-la (e às suas atividades) desde um ponto de vista econômico.

Para além desta introdução e das considerações finais, este artigo apresenta a seguinte estrutura: a primeira seção vai abordar a origem e os desafios da economia criativa, a segunda seção vai ressaltar seu caráter simbólico ou imaterial, a terceira e a quarta seções vão registrar os setores e as estatísticas para diferentes metodologias e países, a quinta seção vai contrapor-lhe a economia tradicional, a sexta seção vai imaginar formas para inovar a economia tradicional, e a sétima e a oitava seções vão mostrar o quanto a ECA já é criativa e (igualmente importante) o quanto 'econômica' ainda pode ser.

0 artigo possui caráter teórico-exploratório e se baseia apenas em revisão bibliográfica. Um aprofundamento com estudo de casos e pesquisa empírica está, portanto, fora de seu escopo.

\section{ECONOMIA CRIATIVA}

Tem havido muito interesse pela importância econômica da criatividade, movimento deflagrado pela Austrália e realmente impulsionado pela Inglaterra (Oliveira et al., 2013, p. 13). A ideia é simples e poderosa: o futuro da riqueza e do desenvolvimento pertenceria às sociedades de indivíduos mais inteligentes, educados, informados, talentosos e criativos. Entretanto, o desafio tem sido duplo: por um lado, definir o conceito e categorizar seus componentes; por outro lado, dirimir imprecisões e responder às críticas.

Comecemos pelas imprecisões. A despeito dos esforços em contrário (Caiado, 2011, p. 15), a economia criativa parece se confundir em alguma medida com a economia do conhecimento, a economia cultural, o capital humano, as indústrias culturais, as indústrias criativas etc. Existiria também uma conexão entre a criatividade e o conhecimento e a inovação, para citar apenas estes. Consequentemente, parte das críticas tem dito respeito à imprecisão das definições e à falta de consenso acerca de quais categorias comporiam esta economia (MinC, 2011, p. 21; Michelini e Méndez, 2013, p. 145).

Alguns autores têm afirmado que a criatividade é um fluxo (processo de transformação e combinação), ao passo que 0 conhecimento é um estoque (Domènech, 2010, p. 51). Outros, que o termo economia é mais amplo e engloba para além das indústrias - geralmente associadas à atividade fabril (MinC, 2011, p. 21-22). Mais importante, a economia criativa tem sido associada com o desenvolvimento social - e, portanto, com a inclusão, a justiça, a democracia e a cidadania (MinC, 2011, p. 34; Madeira, 2014, p. 197). A depender de como se entende separadamente os termos 'criatividade' e 'economia', haverá diferentes possibilidades de apresentação para as categorias componentes da assim chamada 'economia criativa'.

Logo, tem havido certa diversidade metodológica para quantificar a importância econômica dos setores criativos. Um enfoque maior pode recair sobre as indústrias culturais, ou sobre a propriedade intelectual, ou sobre as cadeias de produção/distribuição/ 
consumo correlatas e de apoio, ou até mesmo uma visão mais ampliada pode incluir o turismo e o esporte (Baró, 2009, p. 11). Seja como for, há que se perguntar: a 'economia criativa' é em si uma inovação ou apenas outro rótulo para reorganizar categorias preexistentes? Ainda que não estivéssemos frente a um fenômeno inédito, qual a utilidade de tal abordagem?

\section{ECONOMIA IMATERIAL}

A economia criativa tem sido observada a partir de um conjunto de indústrias (Newbigin, 2010, p. 23), setores (MinC, 2011, p. 22), áreas (Firjan, 2014, p. 7), segmentos (Oliveira et al., 2013, p. 7) ou atividades (Caiado, 2011, p. 18) da economia tradicional já instalada. Por 'observada' entende-se mensurada por meio de transações comerciais formais que envolveram meios de pagamento, geralmente o dinheiro. Contudo, parte do apelo da economia criativa estaria justamente no que não pode ser medido, nem transacionado comercialmente, e que não possuiria expressão monetária.

Embora o termo 'economia criativa' tenha sido cunhado com fins mercadológicos tradicionais (cujo quadro de referência remete a empresas, empregos, impostos, competitividade, crescimento do PIB etc.), a variável 'criatividade' vai introduzir uma série de contrapontos e tensões. Por exemplo, entre: material versus imaterial, escassez versus abundância, preço versus valor, comércio versus intercâmbio, mercado versus esfera pública, consumo versus fruição, propriedade versus usufruto, competição versus cooperação, quantidade versus qualidade, instituições versus pessoas - mesmo se, em última instância, a meta tenha sido sempre a de traduzir o segundo termo em 'unidades' do primeiro termo, em cada um desses pares antagônicos.

Assim, ao mesmo tempo em que o foco dos governos tem sido o "valor econômico e (os) objetivos de mercado" (Caiado, 2013, p. 18), a economia criativa é também a "economia do intangível, do simbólico", caracterizada "pela sua abundância e não pela escassez" (MinC, 2011, p. 24), cujos produtos e serviços geram um tipo de valor que "não pode ser totalmente mensurável em termos monetários" (Oliveira et al., 2013, p. 12), e que eventualmente "não se submetem às leis de mercado" (MinC, 2011, p. 34). Baró (2009, p. 8) a define como um conceito holístico, num mundo cada vez mais dominado "por símbolos, textos, sons e imagens".

Dessa forma, a economia criativa deveria incluir (para além dos termos já referidos) a economia simbólica, a economia linguística (Bourdieu, 1977), a economia imaterial, a economia não-monetária, a economia solidária (Brasil, 2007), a economia cidadã, a economia da dávida (Mauss, 1923-1924) etc. Enumerar todas essas possibilidades tem um objetivo claro: ressaltar a grandeza do conceito, sua amplitude de alcance, sua riqueza fenomenológica. Dito de outro modo: se o real valor gerado pela criatividade pudesse encontrar seu preço (e nem sempre poderá), descobrir-se-ia que a contribuição da economia criativa é muito superior às atuais projeções.

\section{SETORES DA ECONOMIA CRIATIVA}

Baró (2009, p. 11) apresenta uma série de modelos alternativos para classificar as indústrias criativas, ou, como quer 0 Ministério da Cultura do Brasil (MinC), os setores da economia criativa. Por exemplo, o modelo do Reino Unido, o modelo de textos simbólicos, o modelo de círculos concêntricos, o modelo da Organização Mundial de Propriedade Intelectual (WIPO) e o modelo da Conferência das Nações Unidas para o Comércio e o Desenvolvimento (Unctad).

As classificações têm diferido em função da intensidade do uso da criatividade como insumo principal (setores fortemente criativos, setores relacionados aos setores muito intensivos - mas que em si seriam apenas medianamente criativos, e 
setores de apoio ou pouco criativos), em função da submissão aos direitos de autor (o alcance efetivo da lei de copyright), em função da completude da cadeia mercadológica para os produtos e serviços criativos (envolvendo a criação, a produção, a distribuição, o consumo e a sustentabilidade no tempo de todas essas fases; ou, para usar a linguagem do marketing, 0 pré-fabrico, a produção, o produto, o preço, a praça, o ponto de venda, a promoção e o pós-venda) etc.

Por exemplo, o modelo da Unctad é bastante completo, incluindo: design (moda, joalheria, gráfico), publicações (livros e imprensa), artes visuais (pintura, escultura, fotografia), artes cênicas (teatro, dança, circo), audiovisual (cinema, televisão, rádio), novas mídias (softwares, games, meio digital), serviços (publicidade, arquitetura, P\&D), espaços culturais (museus, sítios arqueológicos, bibliotecas), expressões culturais (artesanato, feiras, celebrações) (Baró, 2009, p. 18). Os países têm suprimido ou acrescentado setores, a exemplo do turismo, do esporte, do ensino, da engenharia (em conexão com a arquitetura).

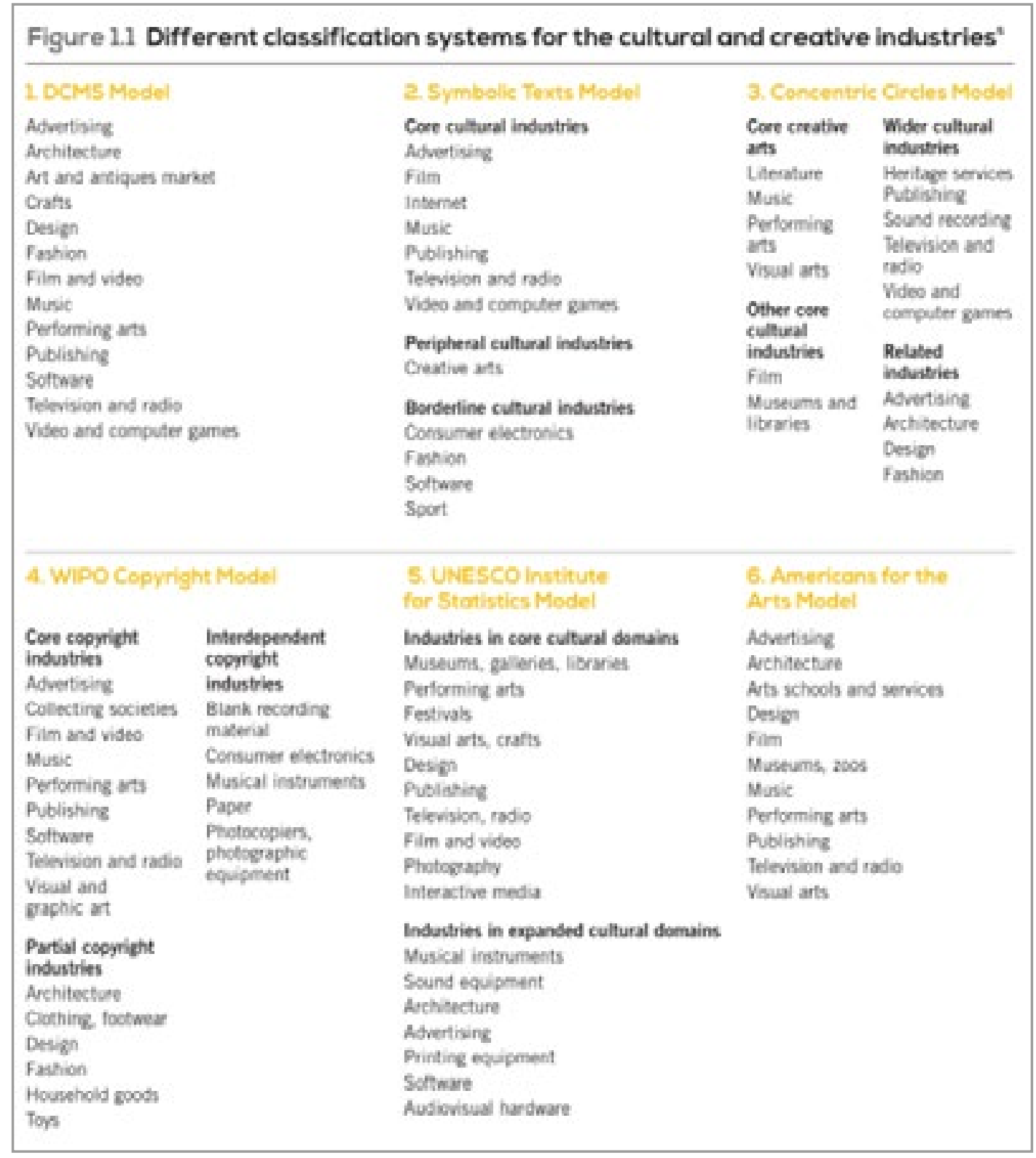

Fonte: Unesco (2013, p. 22).

O Ministério da Cultura do Brasil, em seu Plano da Secretaria da Economia Criativa de 2011, segue o modelo da Unesco (ver Figura 1.1), propondo adaptações à realidade do país. De modo geral há duas categorias: os setores criativos (bipartidos em nucleares e relacionados) e os setores transversais. Optou-se, aqui, por incluir o turismo, o esporte, o lazer e o entretenimento (setores criativos relacionados); além do patrimônio imaterial, a educação, a capacitação, a memória, os equipamentos e os materiais de apoio (setores transversais). Vale mencionar a inclusão das culturas indígenas e afro-brasileiras como componentes culturais da economia criativa (MinC, 2011, p. 27 e 139). 


\section{ECONOMIA CRIATIVA EM NÚMEROS}

De acordo com as metodologias utilizadas para quantificar o fenômeno, dentro de uma abordagem mercadológica, temos os seguintes cenários: no Reino Unido, a economia criativa respondia por 5\% do PIB e 8,3\% do emprego (United Kingdom Government, 2015, p. 7); nos Estados Unidos, por 6,5\% do PIB e 8,5\% do emprego (Baró, 2009, p. 19); na Comunidade Europeia, por 4,2\% do PIB e 3,3\% do emprego (EY, 2014, p. 10); na Espanha, por 3,8\% do PIB e 4,1\% do emprego (Michelini; Méndez, 2013, p. 152); e no Brasil, por 2,6\% do PIB e 1,8\% do emprego (Firjan, 2014, p. 4), ou, quando se considera o setor informal, a 3\% do emprego e 6\% da massa salarial (Oliveira et al., 2013, p. 46).

Internamente, a economia criativa no Brasil está altamente concentrada nas regiões Sul e Sudeste, e também nos grandes centros urbanos - como São Paulo e Rio de Janeiro (Caiado, 2011, p. 29). Os segmentos que mais empregam seriam publicação e mídia impressa, novas mídias, serviços criativos e audiovisual (Oliveira et al., 2013, p. 28). De modo geral, os salários pagos na economia criativa são quase três vezes superiores aos da média geral dos trabalhadores da economia dita tradicional - fato explicado, em parte, pela maior escolaridade proporcional dos profissionais da economia criativa (Firjan, 2014, p. 5).

Setores como publicidade, arquitetura, design e moda empregam $47,38 \%$ da força de trabalho na economia criativa nacional, seguidos por P\&D, TIC e biotecnologia, que empregam juntos 34,29\%, e pelos setores editorial e audiovisual, com 11,36\% dos empregados. Esses três grupos respondem por 93\% do número de empregados do setor criativo brasileiro. Mas há sensíveis diferenças regionais: por exemplo, São Paulo emprega 23,1\% dos trabalhadores criativos em publicidade, ao passo que o Rio de Janeiro concentra sua classe criativa em P\&D, com 29,5\% do total (Firjan, 2014, p. 12 e 17).

Vale notar que, ao que parece, tem-se limitado a economia criativa a uma reorganização nominal de setores que já existiam (e já operavam) na economia tradicional. Aparentemente, a 'economia criativa' é apenas um rótulo para um rearranjo de categorias mercadológicas preexistentes. Cria-se um novo nome e, a partir dos grupos já em funcionamento, selecionam-se setores para preencher a nova categoria. Essa nova forma de agrupar é, contudo, importante desde um ponto de vista de políticas públicas - tanto para entender melhor realidades semelhantes, quanto para fomentá-las com mais propriedade. Ou seja, há uma certa criatividade em propor uma nova expressão, mas a questão é: houve alguma inovação (algum aporte inédito)?

\section{A ECONOMIA TRADICIONAL}

O significado primordial da palavra economia é o de 'gestão da casa'. Começou como uma arte administrativa, uma sabedoria e um bom senso na harmonização dos recursos disponíveis na esfera privada do lar. A exemplo das outras áreas da administração, desenvolveu técnicas, promoveu-se a ciência, e hoje milita no campo tecnológico (o estudo das aplicações das ciências). Seu espectro de ação ultrapassou a casa da família, alcançando primeiro a cidade e depois a nação (entendida como conjunto de cidades) - da esfera privada (no singular) às esferas públicas (no plural).

A ideia é simples: inventariar tudo o que precisa ser feito, catalogar todos os recursos que estão disponíveis, hierarquizar as prioridades, estabelecer um plano de ação e manter um acompanhamento constante durante a execução - para garantir o correto cumprimento e possíveis ajustes de rota. A complicação surge porque os recursos são limitados em sua disponibilidade (existência, acessibilidade e direito de uso), porque sofrem concorrência (várias pessoas os querem), porque são obrigatoriamente combináveis (para obter um bolo é necessário misturar farinha, leite, manteiga, ovos etc.), porque são valorados assimetricamente (gostar ou não, gostar muito ou pouco) e porque são experenciados diferentemente. 
A moeda foi concebida como um denominador comum universal, permitindo que qualquer recurso fosse trocado por qualquer outro (via seu intermédio); e o preço é uma expressão numérica do valor de cada recurso, isto é, sua tradução em unidades de moeda. Assim, na busca pelos recursos necessários para 'gerir a casa', todos devem ir ao mercado: um espaço público de convivência onde os recursos são feitos parcialmente disponíveis. Parcialmente, pois é preciso dar algo (geralmente moeda) para receber algo; mas, principalmente, porque a forma como esse 'algo' se nos apresenta implica informação, conhecimento e comunicação.

Imagine todas as pessoas em sua diversidade de gostos, necessidades e recursos indo ao mercado, em busca do que lhes falta para 'gerir sua casa', e suponha um ente supraindividual (o governo) contabilizando cada uma dessas transações monetárias: eis a economia tradicional. Mas a 'economia criativa' tem sido tratada, até o momento, como um subsetor dessa economia tradicional: novos nomes para velhas atividades. Por exemplo, o subsetor arquitetura, que já existia e era contabilizado, agora passa a fazer parte do novo rótulo 'economia criativa'; mas sua importância relativa na economia tradicional permanece a mesma, tanto do ponto de vista de preço (se não houve salto qualitativo a mudar os valores), quanto do ponto de vista monetário (o quantum de moeda transacionado sob esta categoria).

\section{POR UMA ECONOMIA MAIS CRIATIVA}

Mas a economia tradicional não tem sido muito criativa. Pode-se criticá-la pelo que tem feito (tradução de pessoas e seres em objetos, ou recursos manipuláveis; e tratamento da vida e da sociedade via fórmulas matemáticas - ambos inadequados e insatisfatórios); mas, principalmente, pelo que nãotem feito. De modo geral, tem desconsiderado tudo que escapaà precificação, à monetização, à mercadização. Mesmo quando admite a importância econômica de algo que vinha desconsiderando ao longo da história (e.g. o meio ambiente), o faz apenas no sentido de reafirmar sua miopia: diz que é preciso precificar o fenômeno, monetizá-lo e internalizá-lo no mercado.

Haveria, todavia, pelo menos duas formas de tornar a economia mais criativa: a primeira é diversificando as categorias internas da própria economia, isto é, os preços, as moedas, os mercados, as transações, os recursos; a segunda é a diversificação da própria economia, numa abordagem que ao mesmo tempo resgata sua raiz primordial (de gestão da casa) e a ultrapassa (repensando quem gere o quê e com qual propósito, e acima de tudo redefinindo o que seria esta 'casa' - tendo em mente a tensão entre os pares real/virtual, público/privado, digital/analógico, mercado/comunidade). A 'economia criativa' precisaria, então, transcender o simples reagrupamento de setores ditos dinâmicos e competitivos segundo os critérios da economia tradicional.

Vejamos a diversificação interna. A tecnologia tem propriciado a inovação de recursos materiais (isto é, recursos historicamente inéditos, como um smartphone ou uma variedade de milho transgênico), mas principalmente de recursos imateriais (novas imagens, formas, novos sons, cheiros e sabores proporcionando novos sentimentos, pensamentos, conhecimentos, experiências). Para além das moedas oficiais, como dinheiro e cartão de crédito, tem crescido a oferta de meios de pagamento digitais ou alternativos, válidos e aceitos dentro e fora da internet, em comunidades e para propósitos específicos - indo do bitcoinà doação de trabalho (voluntariado).

Adicionalmente, o mercado como arena ou espaço tem se multiplicado em diversas esferas públicas - caso da internet - e tem igualmente evoluído para incluir intercâmbios variados (do escambo à doação pura e simples, por vezes contrapondo a fruição e o experenciamento ao consumo tradicional). Por outro lado, a composição dos preços tem sofrido enorme dinamismo: em parte devido à publicidade e ao marketing (que agregam valor simbólico aos recursos), em parte devido à revaloração que tem origem na mudança cultural (as pessoas, hoje, dão mais valor ao tempo livre, ao entretenimento e à virtualidade - dentre outros aspectos). 
Já a diversificação externa da economia implicaria inovar, e por inovação entende-se uma ruptura. Ou seja, seria preciso inovação para conceber uma 'economia criativa' diferente de tudo o que temos visto. Por exemplo: uma economia intensiva em valor deveria ter uma circulação proporcionalmente menor de moedas. Uma economia que privilegiasse a qualidade das vivências deveria ser menos recurso-intensiva, no sentido de recursos materiais. Uma economia mais cooperativa tenderia a ser menos competitiva e menos dependente de formas tradicionais de comércio. Em tese, uma economia de interesse público se afastaria do mercado e se aproximaria da política (a 'gestão da casa' comum). Uma economia que promovesse mais intercâmbios (conjunção) do que trocas (disjunção) haveria de ser mais comunicacionalmente intensiva: diálogos, debates e deliberações.

\section{A ECA-USP E A ECONOMIA CRIATIVA}

A Escola de Comunicações e Artes da Universidade de São Paulo (ECA-USP) está diretamente ligada à economia criativa. Em primeiro lugar, porque integra o setor de educação e capacitação; em segundo lugar, porque participa da P\&D (pesquisa e desenvolvimento); e, em terceiro lugar, porque, via extensão, pode gerar diretamente produtos e serviços criativos de alto valor econômico. Em conexão com as áreas de atuação da Faculdade de Arquitetura e Urbanismo da Universidade de São Paulo (FAU-USP), a saber, arquitetura e design, a ECA teria um altíssimo nível de envolvimento com os setores criativos (tomando-se por base o fluxograma da Federação das Indústrias do Estado do Rio de Janeiro (Firjan, 2014, p. 9), caberia excetuar, aqui, a geração de softwares, games, robótica e biotecnologia - por não fazerem parte do portfólio nem da ECA nem da FAU, embora pertençam, sim, à economia criativa).

As áreas de atuação da ECA incluem (www.eca.usp.br): cenografia, direção teatral, interpretação teatral, teoria do teatro, escultura, gravura, multimídia e intermídia, pintura, canto e arte lírica, composição, instrumento, regência, artes cênicas, artes plásticas, música, jornalismo, editoração, publicidade e propaganda, relações públicas, biblioteconomia, turismo, audiovisual, e formação de ator. Junte-se a isso a arquitetura e o design, da FAU (www.fau.usp.br), e é possível ter uma dimensão da importância de ambas no contexto da economia criativa. Segundo estimativas da Firjan (2014, p. 12), apenas os setores de publicidade, arquitetura, design, música, artes cênicas, editorial, audiovisual, expressões culturais e patrimônio e artes responderiam, juntos, por aproximadamente $60 \%$ do emprego em todos os setores criativos do Brasil. Para Oliveira et al. (2013, p. 37), os setores de audiovisual, publicação e mídia impressa (imprensa e editoras), novas mídias (publicidade e internet), serviços criativos (arquitetura, ensino, P\&D, recreação), artes performáticas, design, expressões culturais tradicionais e artes visuais são os que compõem a economia criativa no Brasil, em sua totalidade - gerando, em conjunto, 1,1\% do PIB.

E como a ECA tem lidado com o tema? A economia criativa tem sido o assunto principal de várias pesquisas do Centro de Estudos Latino-Americanos sobre Comunicação e Cultura (Celacc), vinculado à ECA (Barbosa, 2009; Araújo, 2010; Schwab, 2011; Fugita, 2012; Almeida, 2012; Nomelini, 2013). 0 professor Gilson Schwartz tem, inclusive, oferecido cursos que abordam a economia criativa, como, por exemplo, "Economia do audiovisual internacional" (CTR0806) e "Introdução à iconomia" (CTR0716); e o professor Paulo Nassar promoveu, enquanto presidente da Associação Brasileira de Comunicação Empresarial (Aberje), um seminário de "Gestão cultural na economia criativa", em 2012. Alguns outros pesquisadores da ECA têm, igualmente, publicado sobre 0 assunto e temas conexos (Stangl, 2012; Kaufman, 2012; De Marchi, 2014). Um exemplo bem-sucedido da parceria ECA/ FAU foi o projeto Arquigrafia, finalista do Prêmio Brasil Criativo em sua versão de 2014.

\section{POR UMA ECA MAIS ECONÔMICA'}

A partir de uma abordagem da economia criativa, existe uma afinidade natural entre as áreas da ECA e da FAU. Juntas, trabalham em setores tidos como os mais dinâmicos e promissores da economia. Mais, grande parte dos países desenvolvidos

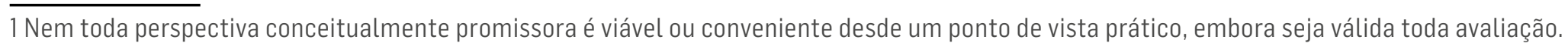


do mundo tem promovido políticas específicas para esses setores, por acreditarem que a próxima etapa do desenvolvimento econômico será intensiva em educação, talento, inovação e criatividade. Portanto, seria de esperar que ambas as instituições atentassem para essa aposta do poder público, se reposicionando sob o prisma de potencial de geração de renda e emprego qualificados que geram, e intensificando suas parcerias.

No cenário internacional, um interessante exemplo é o da Charles Sturt University (www.csu.edu.au), da Austrália, queapresenta sua "ECA" como Escola de Comunicação e Indústrias Criativas, e que chegou a oferecer uma graduação em indústrias criativas (agora descontinuada). A University of the Sunshine Coast, igualmente na Austrália, faz o mesmo; mas ainda hoje oferece um curso de graduação em indústrias criativas (www.usc.edu.au), com majors em publicidade criativa, escrita criativa, drama, design gráfico, design 3-D, design de e-mídia, marketing, estudos de mídia e ecrã, desenvolvimento de serious games. Vale notar a aproximação e convivência pacífica entre criatividade, negócios e indústria eletrônica. Já a Escola de Comunicação da Northwestern University, em Illinois (USA), tem como objetivo "se tornar a líder global em educação para a economia criativa", conjugando programas interdisciplinares, promovendo a inovação e a pesquisa multidisciplinar, educando líderes para a economia criativa e promovendo sua marca mais agressivamente (www.northwestern.edu).

Assim, uma 'ECA mais econômica'2 significa uma escola com uma visão mais sintonizada com a relevância que a 'economia criativa' possui para o desenvolvimento nacional, sensível à importância que o tema já tem - mas que somente agora vem ganhando prioridade na agenda dos formuladores das políticas públicas. Tratar-se-ia menos de instituir cursos ou disciplinas com um enfoque mais gerencial, e mais em reorganizar a estrutura já existente (como vem fazendo a economia tradicional, ao reagrupar setores sob a denominação de economia criativa), além, é claro, de modificar sensivelmente o discurso institucional frente à sociedade. Uma mudança discursiva que, a exemplo do que se percebe alhures, possui um enorme poder para redefinir a própria identidade e o valor intrínseco atribuído.

\section{CONSIDERAÇÕES FINAIS}

Este artigo abordou a economia criativa a partir de um duplo prisma: como os governos a têm encarado, e como as escolas de comunicação a têm incorporado. No caso dos governos, têm-se multiplicado as secretarias e as políticas públicas especificamente pensadas para a área. No caso das escolas de comunicação, ainda parecem ser poucas em número e tímidas quanto à integração do assunto em sua orgânica. A despeito dessa abordagem incipiente, tudo indica que ambos os movimentos tendem a se aprofundar.

Se o desafio dos países tem sido a promoção dos setores criativos na nova economia, o desafio da Escola de Comunicações e Artes da USP passa por incorporar mais completamente os valores envolvidos na noção de 'economia criativa'. Especialmente uma mirada mais "econômica" sobre a criatividade. Um enfoque mais gerencial sobre a criatividade, ancorado em seu potencial de geração de riqueza e desenvolvimento, haveria de influenciar tanto a percepção que a ECA tem de si própria, quanto o discurso que dirige à sociedade.

A exemplo das naturais afinidades que a economia criativa sugere haver entre a ECA e a FAU, seria igualmente precioso estimular as sinergias entre os departamentos internos da Escola de Comunicações e Artes. Para citar apenas um setor, a indústria cinematográfica de Hollywood ilustra bem o potencial do trabalho conjunto de cineastas, escritores, músicos, designers, artistas, relações-públicas, publicitários etc., que, em colaboração com programadores de software, pessoal de

2 Uma 'ECA mais econômica' também significa desenvolver pesquisas que tentem mensurar os impactos sociais e econômicos originados a partir de seus setores criativos. Uma revisão de técnicas utilizadas nesse sentido pode ser encontrada em United Kingdom Government (2011). 
marketing e de negócios, criam enorme riqueza econômica. Isso talvez ajude a entender o porquê de alguns departamentos de comunicação estarem lotados dentro das escolas de negócios em certas universidades.

\section{REFERÊNCIAS}

ALMEIDA, Ana Elisa Pereira de. Cultura e sustentabilidade: um estudo do Plano da Secretaria da Economia Criativa. Monografia (Pós-Graduação Lato Sensu) - Celacc/ECA-USP, 2012.

ARAÚJO, Alexandra Pereira de. A economia criativa e identidade cultural na América Latina. Monografia (Pós-Graduação Lato Sensu) - Celacc/ECA-USP, 2010.

BARBOSA, Adriana. Feira Preta - por uma outra economia: "economia criativa". Monografia (Pós-Graduação Lato Sensu) Celacc/ECA-USP, 2009.

BARÓ, Ezequiel. Les indústries creatives: estat de la reflexió i de l'avaluació del seu pes econòmic a escala internacional. Barcelona: BCF Consultors, octubre 2009.

BOURDIEU, Pierre. L'économie des échanges linquistiques. Langue Française, n. 34, p. 17-34, 1977.

BRASIL. Economia solidária: outra economia acontece. Cartilha da Campanha Nacional de Mobilização Social. Brasília: MTE, Senaes, FBES, 2007.

CAIADO, Aurílio Sérgio Costa (Coord.). Economia criativa na cidade de São Paulo: diagnósticos e potencialidades. São Paulo: Fundap 2011.

DE MARCHI, Leonardo. Análise do Plano da Secretaria da Economia Criativa e as transformações na relação entre Estado e cultura no Brasil. Intercom - Revista Brasileira de Ciências da Comunicação, a. 37, n.1 , São Paulo, jan./jun. 2014.

DOMÈNECH, Rafael Boix. Xarxes de ciutats i localització de l'activitat industrial. In: ALBALATE DEL SOL, Daniel et al. La indústria catalana després de la crisi. Papers d'economia industrial 32. Generalitat de Catalunya, 2010. p. 47-69.

EY. Creating growth: measuring cultural and creative markets in the EU. December 2014.

FIRJAN. Mapeamento da indústria criativa no Brasil. Rio de Janeiro: Firjan, dez. 2014.

FUGITA. Susan. Turismo cultural: um estudo de caso sobre a economia criativa na Vila de Paranapiacaba. Monografia (PósGraduação Lato Sensu) - Celacc/ECA-USP, 2012.

KAUFMAN, Dora. A condição de "agente" do consumidor-internauta. In: FONSECA, Ana Carla et al. Economia criativa: um conjunto de visões. São Paulo: Fundação Telefônica, 2012.

MADEIRA, Mariana Gonçalves. Economia criativa-implicações e desafios para a política externa brasileira. FUNAG, Brasília, 2014.

MAUSS, Marcel. Essai sur le don: forme et raison de l'échange dans les sociétés archaïques. Année Sociologique, seconde série, tome 1, Paris, 1923-1924. 
MICHELINI, J. J.; MÉNDEZ, R. Creative industries, spatial contrasts and urban governance in Madrid. Revista de Geografia e Ordenamento do Território, Centro de Estudos de Geografia e Ordenamento do Território, n. 3, p. 143-170, jun. 2013.

MINC - Ministério da Cultura. Plano da Secretaria da Economia Criativa: políticas, diretrizes e ações - 2011 a 2014. Brasília, DF, 2011.

NEWBIGIN, John. The creative economy. an introductory guide. Creative and Cultural Economy Series 1,. London, UK: British Council, 2010.

NOMELINI, Mariana Destro. // Mostra de Dança das Favelas: o avesso da economia criativa. Monografia (Pós-Graduação Lato Sensu) - Celacc/ECA-USP, 2013.

OLIVEIRA, João Maria de et. al. Panorama da economia criativa no Brasil. Brasília / Rio de Janeiro: Ipea, 2013.

SCHWAB, Maria Eduarda de Moura Gonçalves. Economia criativa e novos arranjos tecnológicos. análise de caso d'A Banda Mais Bonita da Cidade. Monografia (Pós-Graduação Lato Sensu) - Celacc/ECA-USP, 2011.

STANGL, André. McLuhan e o link da Alegria Criativa. In: FONSECA, Ana Carla. et al. Economia criativa: um conjunto de visões. São Paulo, Fundação Telefônica, 2012.

UNESCO. Creative Economy Report. widening local development pathways. Special Edition, 2013.

UNITED KINGDOM GOVERNMENT. The art of the possible: using secondary data to detect social and economic impacts from investments in culture and sport - a feasibility study. DCMS/Arts Council/English Heritage/MLA/Sport England, UK, 2011. Creative industries economic estimates. London: Department for Culture, Media and Sport, January 2015.

Artigo recebido em 5.5.2015 e aprovado em 23.11.2015. 